\title{
Ubiquitin-Conjugating Enzyme Gene
}

National Cancer Institute

\section{Source}

National Cancer Institute. Ubiquitin-Conjugating Enzyme Gene. NCI Thesaurus. Code

C133708.

Genes encoding enzymes that catalyze the second step in the ubiquitination reaction via the transfer of ubiquitin from E1 ubiquitin-activating enzymes to themselves. 